\title{
Understanding the genetics of survival in dairy cows
}

\author{
T. Pritchard, ${ }^{1}$ M. Coffey, R. Mrode, and E. Wall \\ Animal and Veterinary Sciences, Scotland's Rural College, Easter Bush, Midlothian, EH25 9RG, United Kingdom
}

\begin{abstract}
Premature mortality and culling causes great wastage in the dairy industry, as a large number of heifers born never become productive or are culled before their full lactation potential is reached. The objectives of this study were to characterize survival and estimate genetic parameters for alternative longevity traits that considered (1) the survival of replacement heifers and (2) functional longevity of milking cows in the UK Holstein Friesian population, using combined information from the British Cattle Movement Service and milk recording organizations. Mortality of heifers was highest in the first month of life and was proportionately highest in calves born during winter months. Heifer mortality tended to decrease with age until about 16 mo onward; it then gradually increased, expected to be associated with culls due to reproductive failure or problems during pregnancy and calving. In milking cows, days of productive life (DPL) was analyzed as an alternative to the current trait lifespan score. Cows that died in 2009 on average lived for $6.8 \mathrm{yr}$ with an average production of $4.3 \mathrm{yr}$. Heritability estimates were low for both heifer and cow survival and were $\sim 0.01$ and $\sim 0.06$, respectively. The positive genetic correlation between heifer survival with lifespan score (0.31) indicates that bulls that sire daughters with longer productive lives are also likely to have calves that survive and become replacement heifers. However, the magnitude of the genetic correlation suggests that survival in the rearing period and the milking herd are different traits. Genetic correlations were favorable between DPL with somatic cell count and fertility traits indicating that animals with a longer productive life tend to have lower somatic cell count, a shorter calving interval, fewer days to first service, and require fewer inseminations. However, an antagonistic relationship existed between DPL with milk and fat yield traits.
\end{abstract}

Key words: dairy cattle, genetic parameter, heifer, survival

Received October 2, 2012.

Accepted January 10, 2013.

${ }^{1}$ Corresponding author: tracey.pritchard@sruc.ac.uk

\section{INTRODUCTION}

Premature mortality and culling causes great wastage in the dairy industry, as a large number of heifers born never become productive or are culled before their full lactation potential is reached. The dairy herd is divided into the milking herd and the replacement herd, and the interaction between these governs the number of replacements required by the milking herd and, consequently, the number of replacements reared by the dairy producer. The traits frequently recorded are those of the milking cow, whereas the period in the replacement herd is largely unconsidered in genetic evaluations, with the exception of stillbirth and calving ease recorded at birth. Literature is less abundant on the genetic component of heifer survival from $48 \mathrm{~h}$ of birth to first calving.

Dairy heifers only start to generate an income once they enter the milking herd in their first lactation at about $2 \mathrm{yr}$ of age (Wathes et al., 2008). However, many potential replacement heifers do not reach their first lactation as they are either born dead, die during rearing, or fail to conceive (Wathes et al., 2008). The proportion of calves that are born dead or are dead within the first $24 \mathrm{~h}$, generally referred to as stillbirth, has been estimated at about 6 to $8 \%$ in the United Kingdom (Esslemont and Kossaibati, 1996; Wathes et al., 2008; Eaglen et al., 2012) and is more frequent in primiparous cattle (Eaglen et al., 2012). Brickell et al., (2009) found that a further $14.5 \%$ of heifers failed to reach first calving due to calf mortality or conception failure. As well as affecting welfare, premature mortality or culling results in higher replacement costs and limits selection possibilities.

Cows with longer productive lives are expected to be more profitable, as (1) fewer replacement heifers would be required to achieve the same herd output, thus reducing replacement costs (allowing surplus heifers to be sold or enabling a larger proportion of cows to conceive to a beef bull); (2) more offspring are made available from superior cows as herd replacements; (3) more intensive selection is possible; and (4) a greater proportion of potential lactation milk yield is captured from mature cows. Culling, however, is a balancing act between milk production, parity, and genetic progress; 
replacement heifers should have more superior genetics, and SCC and health problems tend to increase with parity. Improved longevity is also expected to lower the environmental effect; for instance, $27 \%$ of methane produced on farms is expected to be produced by herd replacements (Garnsworthy, 2004), thus, by lowering the number of heifer replacements required to maintain herd size by means of improving cow longevity, methane emissions would be reduced.

Lifespan bull proofs were first published in the United Kingdom in 1998 (Visscher et al., 1999). Current evaluations are based on lifespan score, a phenotypic score calculated from actual completed lactations plus predictions of a future survival score based on 3 type traits (mammary composite, legs and feet, fore udder attachment) and SCC. This system was the best that could be implemented at the time, but suffers from the limitation that animals leaving the milk recording system have a lifespan predicted from their last recorded milk test, although some of these animals have been sold to a non-milk recording herd. Also, due to lactation lengths increasing over the years (Pollott, 2011), the comparison of the number of lactations a cow achieves may not be a suitable metric for measuring cow survival.

Cattle passports came into force from July 1996 to improve cattle identification and traceability; in 1998 a computerized cattle tracing system to register all cattle was implemented due to a requirement of the European Union (Regulation 820/97). Births, deaths, and movements are contained in the British Cattle Movement Service (BCMS) database, and it has since been considered for purposes other than what it was originally developed (Ortiz-Pelaez et al., 2008), such as providing useful information on longevity. A minority of studies have estimated genetic parameters for heifer survival with the use of cattle registration and movement data (Hansen et al., 2003; Fuerst-Waltl and Fuerst, 2010; Fuerst-Waltl and Sørensen, 2010). Further, the BCMS data can be used to calculate length of life and length of productive life of the milking cow as alternative longevity traits when the animal's BCMS record is matched to its milk record. The objective of this study was to characterize the data available from BCMS together with milk records to provide information on the survival of replacement heifers from birth to first calving and of milking cows from their first calving. Second, BCMS data were used to estimate genetic parameters for the survival of replacement heifers and longevity of milking cows, in the UK Holstein Friesian population. In addition, the relationship between heifer survival and traits of the milking cow in the United Kingdom was examined.

\section{MATERIALS AND METHODS}

\section{Description of BCMS Database}

All cattle (beef and dairy) in the European Union are individually identified and their movements can be traced throughout their lives (BCMS, 2012). The BCMS database contains records from as early as 1996, but reporting by livestock owners of all births, deaths, and movements was not mandatory until 2001. Currently, animals must be tagged in both ears showing the same unique number that stays with the animal for its lifetime. A cattle passport accompanies the animal and, by law, every animal's record should contain an ear tag number (the animal's unique identity), date of birth, breed, sex, dam ear tag number, movements on and off holdings, details of where it has moved from and to, and date of death. For dairy cattle, a calf should be tagged within $36 \mathrm{~h}$ of birth, whereas for beef cattle, a calf can be tagged up to $20 \mathrm{~d}$ from birth (BCMS, 2012).

The data set obtained from BCMS contained records on animals that had died up until 2009. For this study, only animals that were born since the establishment of BCMS were included in data description and analysis (i.e., from 1996). The data from the BCMS database were validated, matched, and combined with the databases of UK milk recording organizations. A detailed description of the data available on longevity was then undertaken for dairy heifer replacements and milking cows.

\section{Genetic Analysis}

Genetic parameters were estimated for alternative survival traits for (1) dairy heifer replacements and (2) milking cows, made possible by additional information on date of death from BCMS that is not always present in milk records.

Data Set on Survival of Heifer Replacements. Animals born during the 5-yr period, 2002 to 2006, were studied. These years were selected to avoid atypical data due to foot and mouth disease, which affected UK farms in 2001, and to allow time for animals to reach $25 \mathrm{mo}(750 \mathrm{~d})$, the longest observation period studied. The data set obtained from BCMS contained only dead animals. Live contemporaries were extracted from milk recording databases, and the steps taken are illustrated in Figure 1. Only animals from dairy sires and dams with at least $87.5 \%$ Holstein Friesian genes were allowed in order to exclude heifers bred specifically for beef purposes. Recording the sire of an animal is not mandatory in BCMS, therefore sire information was lacking for daughters in the database. 


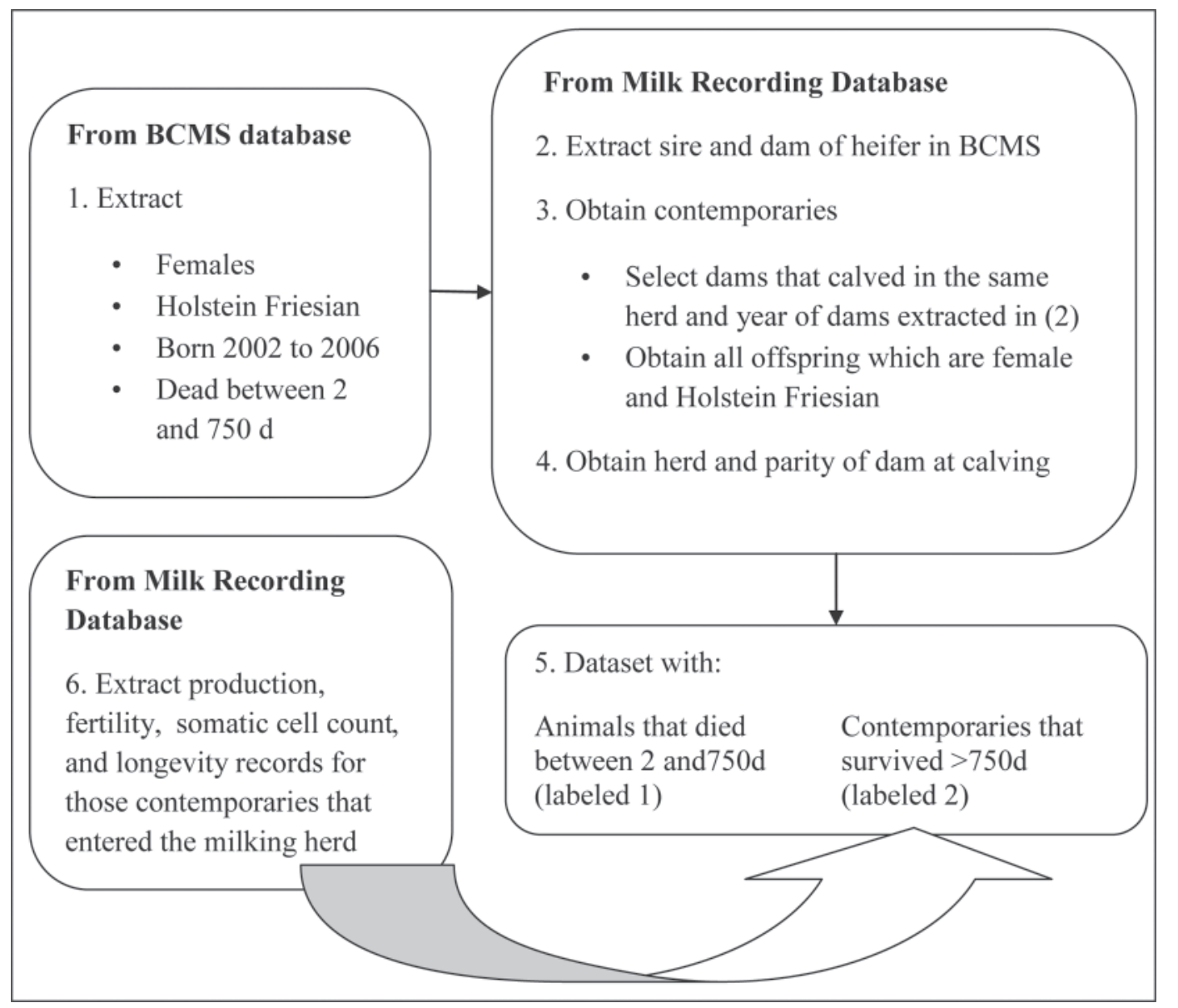

Figure 1. Extraction of data for genetic analysis of survival in replacement heifers (2 to $750 \mathrm{~d}$ ). BCMS = British Cattle Movement Service.

Consequently, BCMS data were only used when animal identities could be matched with those in the milk recording organization's database with known dairy sires and dams. Animals were born in milk-recorded herds that either had lactation records (1a) or had died or been culled before having the opportunity to calve (1b), as illustrated in Figure 2.

Survival of heifers at different age points -2 to $30 \mathrm{~d}$, 2 to $90 \mathrm{~d}, 2$ to $180 \mathrm{~d}, 2$ to $450 \mathrm{~d}$, and 2 to $750 \mathrm{~d}$-were estimated from separate data sets. Survival was treated as a binary trait with an assigned value of 1 if the animal was born alive and died between $\mathrm{d} 2$ and the specified age point, and 2 if it survived longer than the specified age point. Deaths recorded earlier than $2 \mathrm{~d}$ were not included as these could be defined as stillbirth, a separate trait which is not part of this study, and deaths before ear tagging were expected to be underrecorded. The largest data set (with observation period from 2 to $750 \mathrm{~d}$ ) was split either into 2 subsets $(2$ to $180 \mathrm{~d}$ and 181 to $750 \mathrm{~d}$ ) or 3 subsets ( 2 to $180 \mathrm{~d}, 181$ to $450 \mathrm{~d}$, and 451 to $750 \mathrm{~d}$ ) to provide additional subsets containing dead animals and their contemporaries for bivariate and trivariate analyses treating different time periods during the rearing period as separate traits.

Before data editing, preliminary analysis involved examination of the data set to estimate mortality rates. Although the reason for death was not indicated, the premises of death was recorded and showed that the majority of animals had died on an agricultural holding rather than the slaughterhouse. Deaths on the farm are more likely to be involuntary, whereas deaths at the slaughterhouse could be considered intentional; however, both would be wastages to the system, but might be regarded as different aspects of heifer survival. Therefore, analyses included all animals that were dead at the specified age point (which included animals that died on an agricultural holding only or all premises of death) and their contemporaries born in the same herd-year group. The data were then edited for the purposes of genetic parameter estimation. Known freemartins were removed, however, those freemartins not recorded with a male twin could not be identified. 


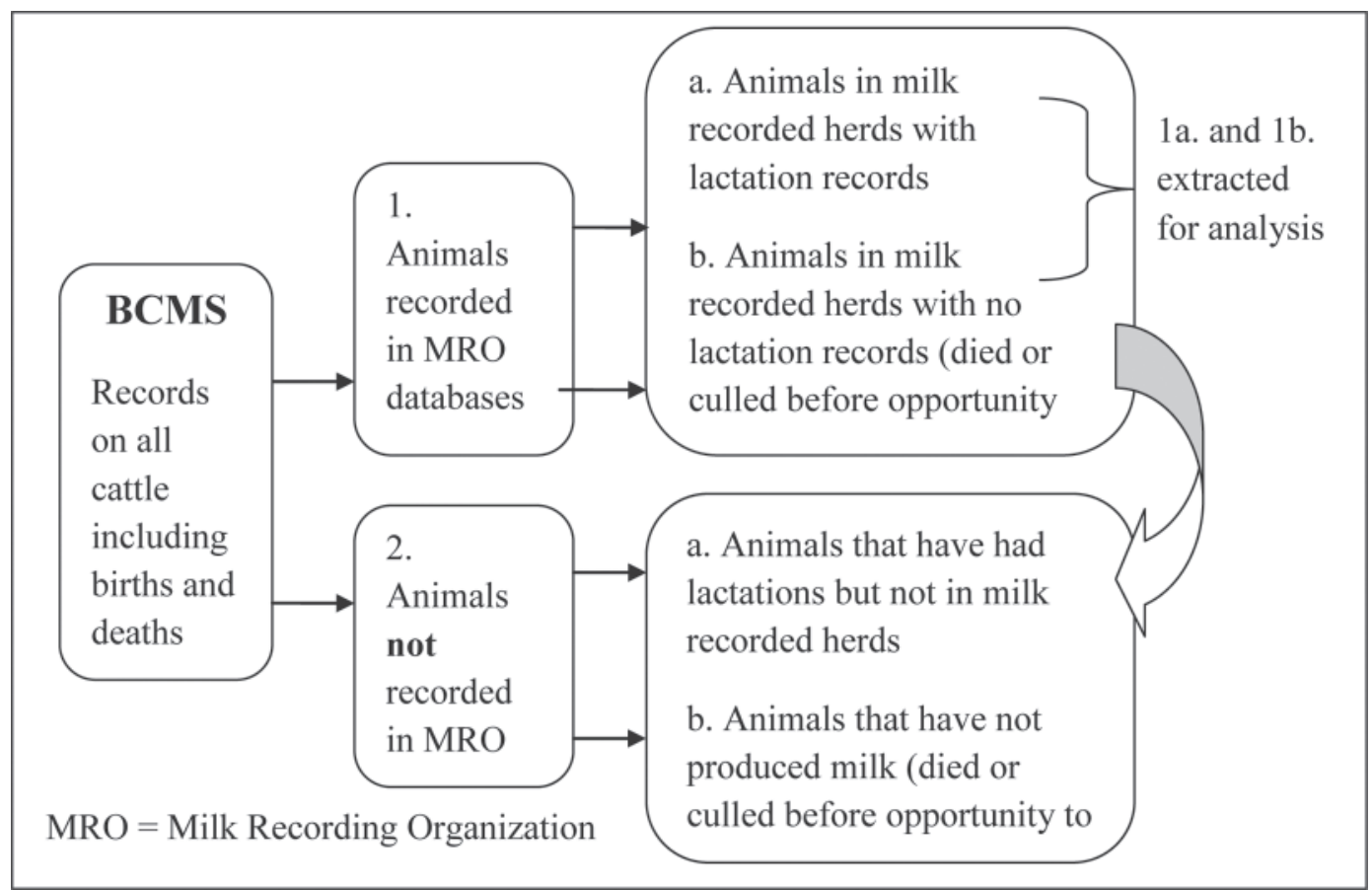

Figure 2. Illustration of non-milk-recorded and milk-recorded animals in the British Cattle Management Service (BCMS) database.

Calving ages of dams for first, second, third, fourth, and fifth parities were within the ranges of 18 to $42 \mathrm{mo}$, 30 to $56 \mathrm{mo}, 42$ to $70 \mathrm{mo}, 54$ to $84 \mathrm{mo}$, and 66 to 98 mo, respectively. Later parities (up to 8) were grouped with the fifth parity and were allowed a range of 78 to 132 mo. Each bull was required to have at least 20 daughters in the data set and the first 300 daughters of proven bulls were selected to prevent data being dominated by few widely used bulls. Also, each bull was required to have both dead and live progeny in the data set (at the specified age point) and at least 5 animals were required per herd-year. The data sets analyzed for survival at 30,90, 180, 450, and $750 \mathrm{~d}$ are summarized in Table 1. Where available, milk records and lifespan score (LS) were amalgamated with the largest data set for heifer survival 2 to $750 \mathrm{~d}$. For the complete data set, a 6-generation full pedigree of the sire consisting of 9,446 animals was used in the analyses.
Data Set on Survival of Milking Cows. Two alternative functional longevity traits were defined: (1) the number of days alive from birth until death [days of life (DL)] and (2) the number of days alive from day of first calving until death [days of productive life (DPL)]. The data set included dead animals only, and years of birth were restricted to a 5-yr period from 1996 to 2000, thereby minimizing the likelihood of live contemporaries. All animals were Holstein Friesian breed, had calving and milk records for their first lactation, and were aged between 18 and 42 mo at first calving. Each bull had at least 40 daughters in the data set, only the first 300 daughters born of a proven bull were selected, and at least 5 animals were required per herdyear-season. The calving year was defined as April to March, and each year was split into 2 seasons (April to September and October to March). After editing, the data set contained 127,737 animals sired by 1,704 bulls.

Table 1. Summary of data sets for the analysis of heifer survival at 30, 90, 180, 450, and $750 \mathrm{~d}$, including all premises of death (animals that died on an agricultural holding in parentheses)

\begin{tabular}{lcccc}
\hline Trait & Animals (no.) & Sires (no.) & Dead (\%) & $\begin{array}{c}\text { Dead at } \\
\text { slaughterhouse (\%) }\end{array}$ \\
\hline 2 to $30 \mathrm{~d}$ & $59,478(57,734)$ & $833(818)$ & $6.9(6.7)$ & 0.3 \\
2 to $90 \mathrm{~d}$ & $85,510(83,142)$ & $1,277(1,252)$ & $8.9(8.8)$ & 0.4 \\
2 to $180 \mathrm{~d}$ & $98,072(95,850)$ & $1,459(1,432)$ & $10.5(10.2)$ & 0.4 \\
2 to $450 \mathrm{~d}$ & $107,942(105,572)$ & $1,581(1,562)$ & $12.1(11.7)$ & 0.6 \\
2 to $750 \mathrm{~d}$ & $117,515(112,163)$ & $1,691(1,657)$ & $13.7(12.8)$ & 1.5 \\
\hline
\end{tabular}


The sire and animal pedigrees contained 5 generations with 7,222 and 413,118 animals, respectively. To understand the relationship between the survival of milking cows and other economic traits in the United Kingdom, national profit index joint analysis of survival was carried with these economic traits: milk, fat, and protein yields, $\log _{\mathrm{e}}$-transformed lactation average somatic cell count (LSCC), calving interval, and nonreturn rate at d 56.

Statistical Analysis. Genetic parameters were estimated in ASReml (Gilmour et al., 2006), using a sire model for all traits. Heritability estimates using a sire model were calculated as 4 times the sire variance component divided by the phenotypic variance (sire plus residual variance).

Univariate sire analyses were carried out for all heifer survival traits. The fixed effects and covariates included for each trait were parity of dam (5 classes: $1,2,3,4,5+$ ), age of dam at calving (in months), month of birth (12 classes), birth type (2 classes: single, multiple), nonadditive effects heterosis $($ mean $=15.2 \%)$ and recombination loss $($ mean $=10.6 \%)$, and herd-year. Heterosis and recombination loss, which considered only 2 breeds (Holstein and Friesian), were calculated as follows (Wall et al., 2005):

$$
\begin{gathered}
\text { heterosis }=\mathrm{P}_{\mathrm{S}}\left(1-\mathrm{P}_{\mathrm{D}}\right)+\mathrm{P}_{\mathrm{D}}\left(1-\mathrm{P}_{\mathrm{S}}\right), \\
\text { recombination loss }=\mathrm{P}_{\mathrm{D}}\left(1-\mathrm{P}_{\mathrm{D}}\right)+\mathrm{P}_{\mathrm{S}}\left(1-\mathrm{P}_{\mathrm{S}}\right)
\end{gathered}
$$

where $\mathrm{P}_{\mathrm{S}}$ and $\mathrm{P}_{\mathrm{D}}$ are the proportion of Holstein for the sire and dam, respectively. Random effects included the sire of the animal and the residual error.

Genetic parameters were estimated for DPL and DL using a model based on that used for the current lifespan trait (Visscher et al., 1999). Records for DPL and DL were divided by $365 \mathrm{~d}$ for analysis to obtain variances of a similar size to LS. All lifespan traits were defined as functional longevity traits, and were thus corrected for milk yield. Sire was fitted as a random effect and nongenetic effects included month of calving, linear and quadratic of age at first calving, deviation of milk yield from the mean of contemporaries, heterosis, recombination, and herd-year-season. Animal model estimation of parameters was also carried out on the same data set for the purposes of comparison.

Bivariate analyses between heifer survival (2 to 750 d) and either DPL, LS, production traits, LSCC, or fertility traits were carried out. The residual error covariances in the bivariate analyses were fixed at zero, as it was not estimable given that animals scored 1 (i.e., dead at $750 \mathrm{~d}$ ) had no records for traits as a dairy cow. The model for production, LSCC, and fertility included the random effect for sire and the fixed effects herd- year-season, month of calving, and age at calving as a covariate (months).

\section{RESULTS}

\section{Data Description - Heifer Replacements}

Recording of Sire and Dam Identities in $\boldsymbol{B C M S}$. In contrast to the almost $100 \%$ recording of dam, a compulsory entry, the percentage of calves with sire records, which is a voluntary entry, was low. From animals that died within $750 \mathrm{~d}$ of birth $(91,957$ animals), $11.9 \%$ had sires recorded. Recording of sire was low as 3\% in 1998 but increased each year up until 2005 to $15 \%$; however, after 2005 the number of records tended to decrease.

Premises of Death Recorded in BCMS. Records on premises of death showed that the majority of animals dying before first calving were recorded dead on the agricultural holding $(\sim 90 \%)$ and the remaining animals were mostly recorded dead at the slaughterhouse $(\sim 10 \%)$. Figure 3 shows that the proportion of animals taken to slaughter increased slightly in later stages of the heifer-rearing period.

Month of Birth and Death. Calving tends to be seasonal and generally peaks in August, September, and October for dairy calves, as shown in Figure 4. Stillbirth is often defined as those animals that die in the first $48 \mathrm{~h}$ of birth. Out of those animals that died before 25 mo of age, 2,370 animals (2.6\%) died before $2 \mathrm{~d}$ of age. However, it is expected that stillbirth is under-recorded, as animals do not need to be reported if they die before they are tagged. Newborns were at the highest risk of death, with the highest number of deaths taking place in the first $2 \mathrm{~d}$ of life. A slight decrease in the frequency of deaths was observed from the first $2 \mathrm{~d}$ of life, but this peaked at $10 \mathrm{~d}$ after birth and as heifers grew older the level of deaths decreased. Frequency of deaths gradually increased from mo 16 onwards, which coincides with the increasing number of animals sent to the slaughterhouse in the same period. Figure 4 shows losses between 2 to $30 \mathrm{~d}$ of age were greatest for animals born in winter months and lowest for births during the summer.

Linking to Insemination Data. First insemination generally takes place around 15 mo of age. Insemination data were matched to those animals that had survived for 12 mo but were dead at 25 mo. It was found that over $10 \%$ of these animals had at least one insemination record, and some of these had repeat records.

\section{Data Description - The Milking Cow}

The average age at first calving, 29 mo of age, has not changed in the last $10 \mathrm{yr}$. However, the data are 


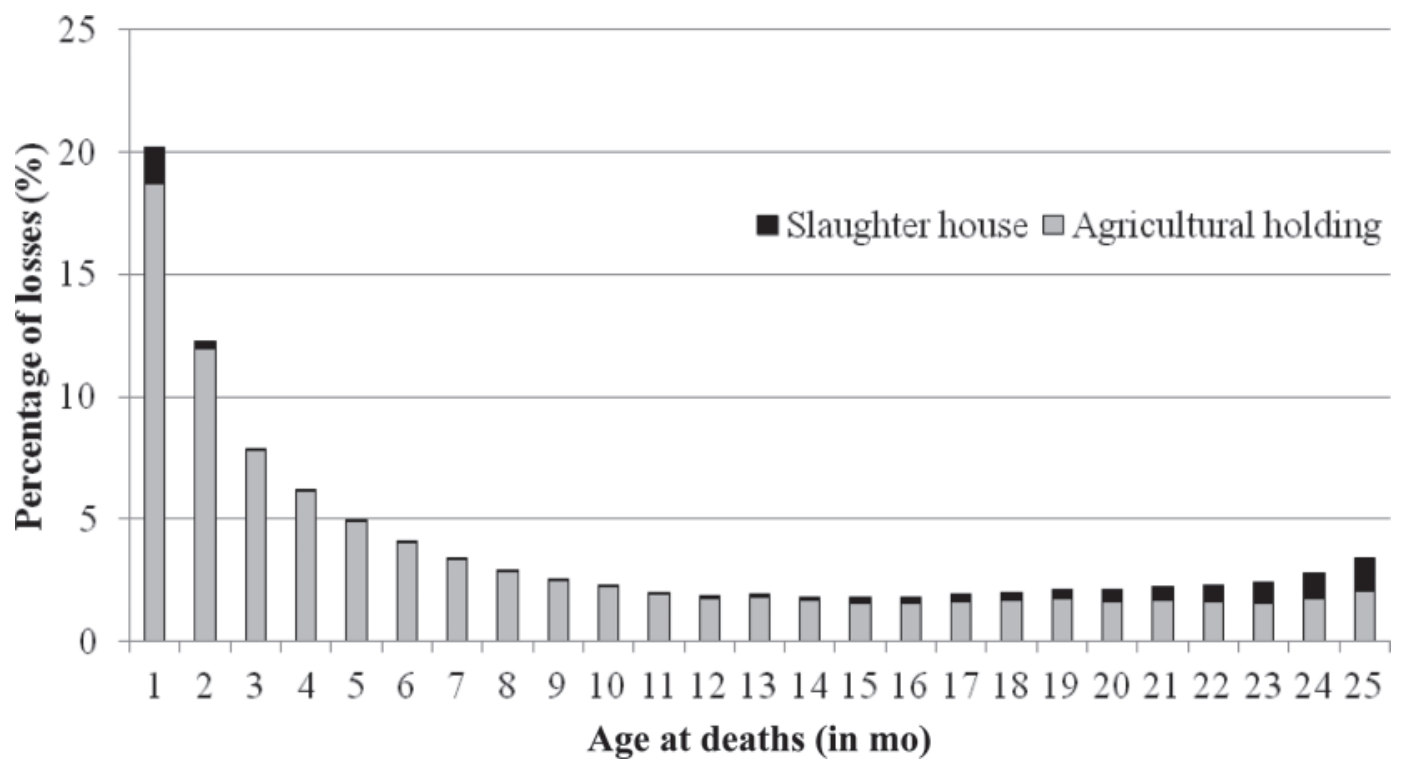

Figure 3. Heifer losses in the first 25 mo for animals born between 2002 and 2006 .

skewed and the highest numbers of heifers give birth at 25 mo. In 2009, the average number of calvings of a dairy cow was 3.6 and the average number of years of production (from first calving till death) was $4.3 \mathrm{yr}$. Figure 5 shows the mean DL and DPL of milking cows for years of death 2004 to 2009. For animals that died in 2009, the mean number DL and DPL were 2,472 and 1,578 d, respectively. In Figure 5, line plots for DL and DPL appear parallel because the mean age at calving ( $\sim 29 \mathrm{mo})$ has remained similar over the years. The count falls in 2009 as the cutoff point for data extraction was during this year. The difference between date of last milk recording and date of death in some cases can be quite long (e.g., 1 or 2 yr); however, on average the difference was about $185 \mathrm{~d}$ (6 mo) in 2009 .

Figure 6 shows the frequency of culling by months of productive life. Five prominent peaks were observed around 13, 26, 38, 50, and $62 \mathrm{mo}$ from first calving

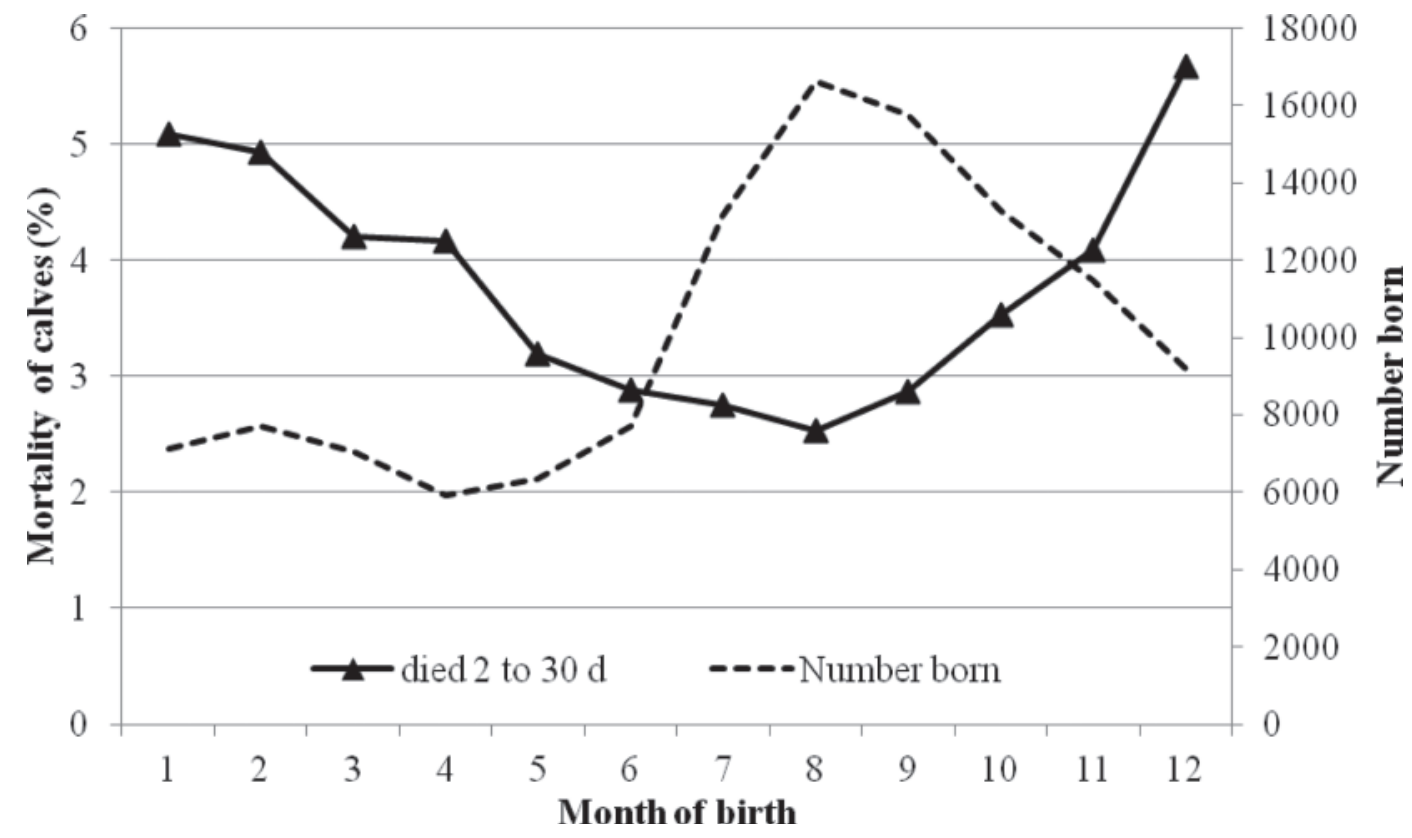

Figure 4. Calf losses by month for calves born in the first month of life (2 to 30 d) during a 10-yr period (1999 to 2008$)$. 


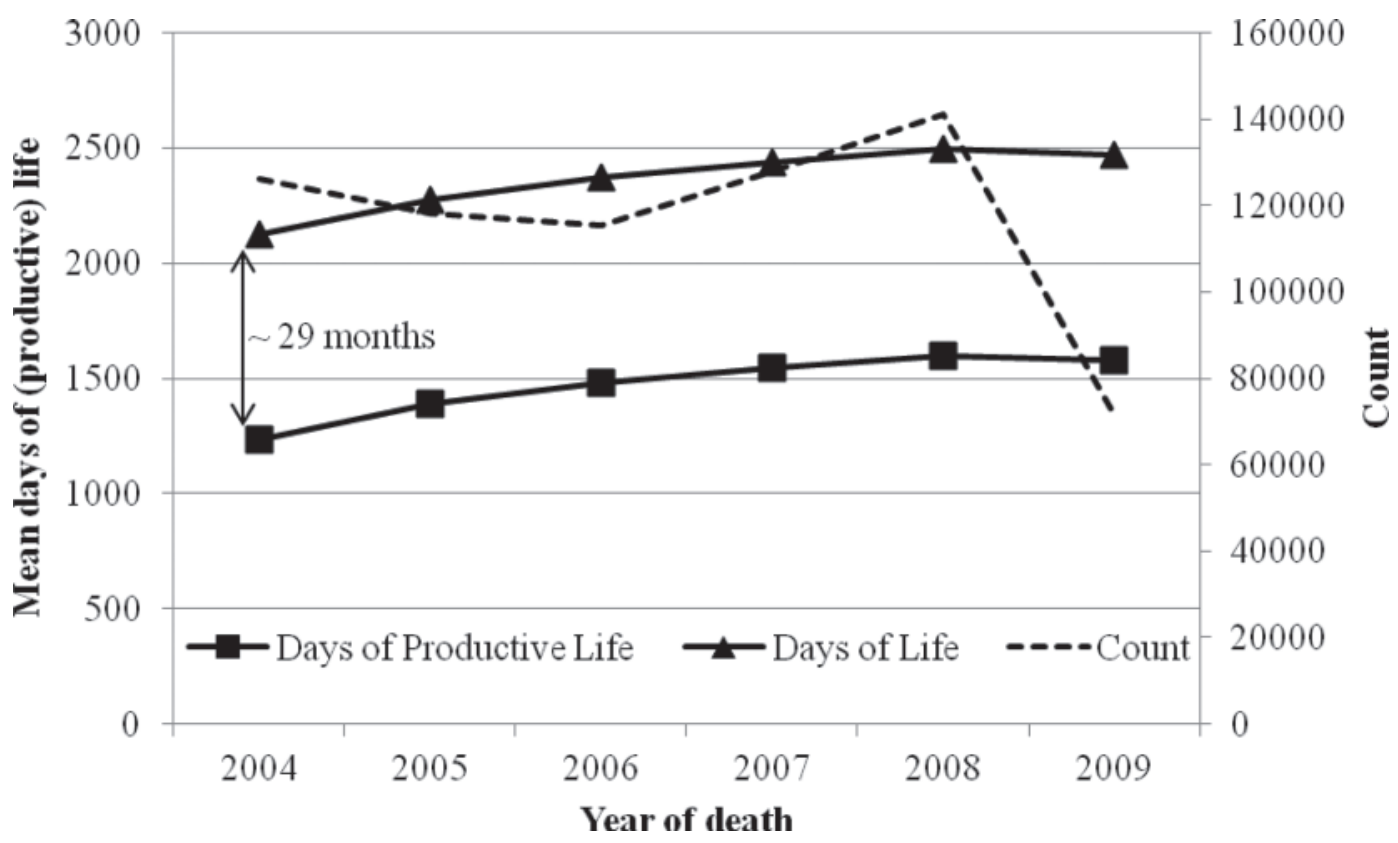

Figure 5. Days of life calculated from milk recording data and British Cattle Management Service data.

(about a year difference between each peak), which would be expected to be at the end of a lactation or the start of a new lactation. The data showed that 30 and $70 \%$ of deaths were recorded as either on the agriculture holding or at the slaughterhouse, respectively.

\section{Genetic Analysis - Survival of Heifer Replacements}

Percentage of heifer mortality (including culling) from 2 to $750 \mathrm{~d}$ of age ranged from 1.2 to $48.1 \%$ in bulls with at least 50 daughters. Estimated genetic parameters for the observation periods ranging from 2 to $30 \mathrm{~d}$ to 2 to $750 \mathrm{~d}$ are given in Table 2. Heritability estimates were low $(\sim 1 \%)$ for all survival traits. The highest heritability estimates were obtained from the longest observation period, 2 to $750 \mathrm{~d}$, and heritability estimates tended to increase with length of observation period. The heritability estimates of the data sets with the shortest observation periods ( 2 to $30 \mathrm{~d}$ and 2 to $90 \mathrm{~d}$ ) and the observation periods that started at a

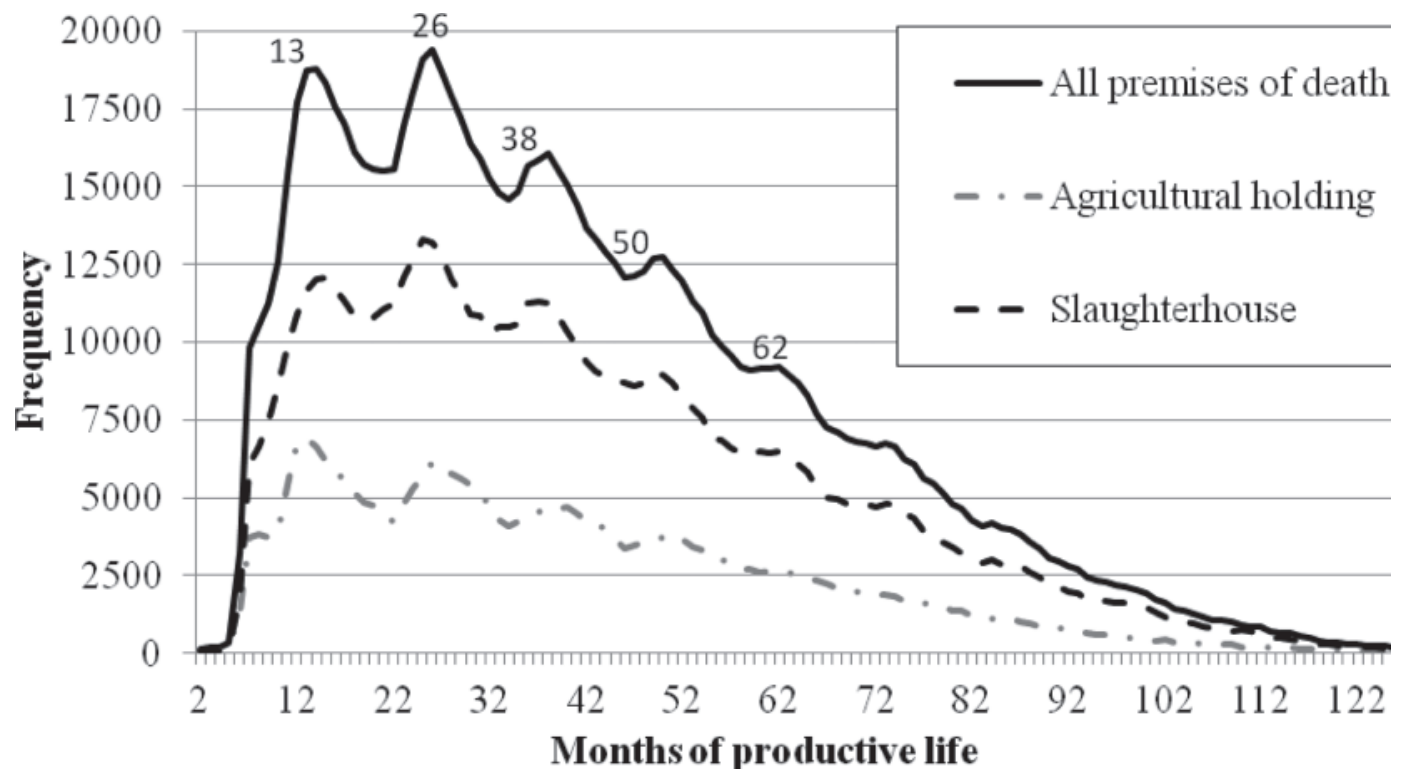

Figure 6. Frequency of losses by month from first calving. 
Table 2. Estimates of variance components ${ }^{1}$ from univariate analysis of heifer survival at 30, 90, 180, 450, and $750 \mathrm{~d}$

\begin{tabular}{|c|c|c|c|c|c|}
\hline Trait & $\sigma_{s}^{2}$ & $\sigma_{e}^{2}$ & $\sigma_{p}^{2}$ & $h^{2}$ & $h^{2} A H$ \\
\hline 2 to $30 \mathrm{~d}$ & 0.00002 & 0.0634 & $0.063 \pm 0.0004$ & $0.002 \pm 0.002^{\mathrm{NS}}$ & $0.002 \pm 0.002^{\mathrm{NS}}$ \\
\hline 2 to $90 \mathrm{~d}$ & 0.0001 & 0.0802 & $0.080 \pm 0.0004$ & $0.005 \pm 0.003^{\mathrm{NS}}$ & $0.005 \pm 0.003^{\mathrm{NS}}$ \\
\hline 2 to $180 \mathrm{~d}$ & 0.0002 & 0.0921 & $0.092 \pm 0.0004$ & $0.011 \pm 0.003$ & $0.012 \pm 0.003$ \\
\hline 2 to $450 \mathrm{~d}$ & 0.0003 & 0.1040 & $0.104 \pm 0.0004$ & $0.011 \pm 0.003$ & $0.014 \pm 0.004$ \\
\hline 2 to $750 \mathrm{~d}$ & 0.0004 & 0.1156 & $0.116 \pm 0.0005$ & $0.013 \pm 0.003$ & $0.015 \pm 0.004$ \\
\hline 181 to $450 \mathrm{~d}$ & 0.0001 & 0.0570 & $0.057 \pm 0.0004$ & $0.010 \pm 0.005^{\mathrm{NS}}$ & $0.007 \pm 0.005^{\mathrm{NS}}$ \\
\hline 181 to $750 \mathrm{~d}$ & 0.00008 & 0.0708 & $0.071 \pm 0.0004$ & $0.005 \pm 0.003^{\mathrm{NS}}$ & $0.002 \pm 0.003^{\mathrm{NS}}$ \\
\hline 451 to $750 \mathrm{~d}$ & 0.00004 & 0.0568 & $0.057 \pm 0.0004$ & $0.003 \pm 0.004^{\mathrm{NS}}$ & not estimable \\
\hline
\end{tabular}

later age (i.e., $180 \mathrm{~d}, 450 \mathrm{~d})$ were not significant $(P>$ $0.05)$. Heritability estimates were very similar between analyses, with regard to premises of death, but were slightly lower when slaughtered animals were included. Genetic correlations between the observation period 2 to $180 \mathrm{~d}$ with 181 to $450 \mathrm{~d}$ and 181 to $750 \mathrm{~d}$ were $0.60 \pm$ 0.28 and $0.94 \pm 0.27$, respectively. Bivariate analyses of these observation periods resulted in higher heritability estimates for all traits.

The genetic correlation between heifer survival at 2 to $750 \mathrm{~d}$ with LS was positive and moderate $(0.31 \pm$ $0.14)$. Genetic correlations between heifer survival with milk 305-d yield, protein 305-d yield, and fat 305-d yield were $0.23 \pm 0.10,0.25 \pm 0.11$, and $0.25 \pm 0.11$, respectively. However, the genetic correlations between heifer survival with fertility traits and LSCC were not significant $(P>0.05)$.

\section{Genetic Analysis - Survival of the Milking Cow}

Estimated genetic parameters for DPL, DL, and LS are given in Table 3. All heritability estimates were low, ranging from 0.05 to $0.06(P<0.01)$. The 2 alternative traits, DPL and DL, appeared to be virtually the same trait with the same heritability of 0.06 , thus further results and discussion will concentrate on DPL. The present trait, LS used in genetic evaluations had a slightly lower heritability of 0.05 . Bivariate analysis between DPL and LS showed that the 2 traits were genetically very highly correlated (0.97). Results from the animal model were slightly higher than the sire model $(0.064 \pm 0.006$ compared with $0.061 \pm 0.006)$, but not significantly different. The animal model was computationally more demanding for both time and space compared with the sire model (i.e., $78 \mathrm{~h}$ compared with 8 min with each having a pedigree of 5 generations).

Table 4 shows results from the bivariate analyses between DPL with production, somatic cell count, and fertility traits. The strongest genetic correlations with DPL were calving interval $(-0.43)$, lactational somatic cell count $(-0.39)$, number of inseminations $(-0.36)$, and milk yield $(-0.36)$.

\section{DISCUSSION}

\section{Heifer Survival Before Entering the Milking Herd}

Still birth was not investigated as a trait in this study as it was found to be under-recorded in BCMS and deaths in the first $2 \mathrm{~d}$ of life accounted for only $2.2 \%$ of deaths up to 25 mo of age. The definition of stillbirth varies between studies (Philipsson et al., 1979), but is generally defined as a calf that is dead before (between 260-d gestation and full term), during, or up to 48 $\mathrm{h}$ after parturition (Berglund et al., 2003). In 3 UK studies the incidence of stillbirth in the first $24 \mathrm{~h}$ after

Table 3. Variance component estimates of lifespan score (LS), days of productive life (DPL), and days of life (DL) using linear sire and animal models

\begin{tabular}{llcccc}
\hline Model & Trait & $\begin{array}{c}\text { Residual } \\
\text { variance }\end{array}$ & $\begin{array}{c}\text { Genetic } \\
\text { variance }\end{array}$ & $\begin{array}{c}\text { Phenotypic } \\
\text { variance }\end{array}$ & $h^{2}$ \\
\hline Sire & LS & $4.974 \pm 0.021$ & $0.270 \pm 0.030$ & $5.042 \pm 0.022$ & $0.054 \pm 0.006$ \\
& DPL $^{1}$ & $3.798 \pm 0.016$ & $0.236 \pm 0.024$ & $3.857 \pm 0.017$ & $0.061 \pm 0.006$ \\
\multirow{2}{*}{ Animal } & DL $^{1}$ & $3.799 \pm 0.016$ & $0.236 \pm 0.024$ & $3.858 \pm 0.017$ & $0.061 \pm 0.006$ \\
& LS & $4.786 \pm 0.028$ & $0.263 \pm 0.026$ & $5.049 \pm 0.022$ & $0.053 \pm 0.005$ \\
& DPL $^{1}$ & $3.620 \pm 0.023$ & $0.246 \pm 0.022$ & $3.866 \pm 0.017$ & $0.064 \pm 0.006$ \\
\hline
\end{tabular}

${ }^{1}$ Records were divided by $365 \mathrm{~d}$ for analysis. 
Table 4. Genetic, residual, and phenotypic correlations between days of productive life with production, fertility, and LSCC (in lactation 1)

\begin{tabular}{lcrr}
\hline Item $^{1}$ & $\begin{array}{c}\text { Genetic } \\
\text { correlation }\end{array}$ & $\begin{array}{c}\text { Residual } \\
\text { correlation }\end{array}$ & $\begin{array}{c}\text { Phenotypic } \\
\text { correlation }\end{array}$ \\
\hline MY & $-0.36 \pm 0.049$ & $-0.04 \pm 0.004$ & $-0.05 \pm 0.005$ \\
FY & $-0.17 \pm 0.056$ & $0.06 \pm 0.004$ & $0.05 \pm 0.004$ \\
PY & $0.10 \pm 0.056$ & $0.15 \pm 0.004$ & $0.15 \pm 0.004$ \\
LSCC & $-0.39 \pm 0.055$ & $-0.09 \pm 0.003$ & $-0.10 \pm 0.003$ \\
CI & $-0.43 \pm 0.083$ & $-0.02 \pm 0.004$ & $-0.02 \pm 0.004$ \\
DFS & $-0.30 \pm 0.089$ & $-0.02 \pm 0.004$ & $-0.02 \pm 0.004$ \\
NINS & $-0.36 \pm 0.113$ & $-0.01 \pm 0.004$ & $-0.02 \pm 0.004$ \\
NR & $0.13 \pm 0.147^{\text {NS }}$ & $0.01 \pm 0.004$ & $0.01 \pm 0.004$ \\
${ }^{1}$ MY = milk 305-d yield; PY = protein 305-d yield; FY = fat 305-d yield; LSCC = Loge lactational average \\
somatic cell count; CI = calving interval; DFS = days to first service; NINS = number of inseminations; NR \\
$=$ non-return rate at 56 d. \\
Ns Genetic correlation was not significant.
\end{tabular}

parturition was estimated around 6 to $8 \%$ (Esslemont and Kossaibati, 1996; Brickell et al., 2007; Eaglen et al., 2012 ) and $8.2 \%$ in a US study (Lombard et al. 2007). Interestingly, in those herds that recorded deaths before $2 \mathrm{~d}$ of age, the mortality was $7.4 \%$ - close to other UK estimates.

Wathes et al. (2008) defined neonatal mortality as calves that were born alive but die between $24 \mathrm{~h}$ and $28 \mathrm{~d}$ and estimated mortality as $3.4 \%$ from a survey of 19 UK herds. In the present study, $3.1 \%$ of animals had died between 2 to $28 \mathrm{~d}$ of age, a similar mortality to the above study. Calf mortality is well documented to be highest in the first month of life (Waltner-Toews et al., 1986; Svensson et al., 2006) and the main causes are commonly reported due to gastrointestinal diseases (Menzies et al., 1996; Svensson et al., 2006) or associated with dystocia (Wells et al., 1996a; Lombard et al., 2007). In addition, about $2 \%$ of heifers are expected to be born as freemartins (twin to a bull), which are generally culled soon after birth (Wathes et al., 2008). However, where resorption of the male fetus twin during gestation had occurred, some freemartins might not be identified until they are found to be barren (usually at first mating). It was found that calves born during the winter period had greatest risk of mortality in their first month of life, as reported in other studies (Wells et al., 1996b; Van der Fels-Klerx et al., 2002; Svensson et al., 2006). One reason could be due to limited housing, a problem more likely during winter in herds where animals graze outside for part of the year. During times of limited housing, larger groups of calves might be housed together, leading to more calf-to-calf contact and allowing easier spread of infection, which generally affects less competitive (smaller) calves that are more vulnerable to infection. Although results were not significant, Svensson et al. (2006) found that pens with small groups of animals were associated with lower mortality. Also, cold stress can decrease the absorption rate of immunoglobulins in the calf; dairy calves are born with little body fat and thus require more energy intake to maintain body temperature and a healthy immune system when temperatures are low. Other studies have also reported seasonal changes in colostrum quality, which could be associated with seasonal differences of losses (Gulliksen et al., 2008; van der Poel et al., 1999).

We found that from 1 to $6 \mathrm{mo}$ and 6 to $15 \mathrm{mo}, 5.4$ and $2.5 \%$ of heifers had died, respectively. In another study of the BCMS database, calf mortality ranged from 2 to $6 \%$ in the first 6 mo in different regions of the United Kingdom (Ortiz-Pelaez et al., 2008); however, the study also included beef and male cattle and thus cannot be directly comparable to the present study. Respiratory disease is a major cause of death from $1 \mathrm{mo}$ of age onward (Menzies et al., 1996; Sivula et al., 1996; Svensson et al., 2006). From 6 to 15 mo of age, Wathes et al. (2008) obtained mortality estimates of $2.6 \%$ from one farm and $3.5 \%$ from 19 farms, which are comparable to the present study (2.5\%). Later mortality, from 9 mo onward, has been associated with trauma, such as accidents causing injury, and 15 mo onward has been reported to be related to pregnancy and calving (Svensson et al., 2006). From 15 to 25 mo, a further loss of $2.7 \%$ of heifers was noted. In this study, the rise in animals slaughtered after $16 \mathrm{mo}$ at the abattoir for beef is likely due to heifers deemed unsuitable as breeding replacements, freemartins, or having failed to conceive. Evidence of this was shown by a proportion of animals that had died before first calving but had insemination data. Overall, heifer losses from 2 d to 25 mo were $13.7 \%$, which is in line with another United Kingdom study of losses before first calving with an estimate of 14.5\% (Brickell et al., 2009).

\section{Lifespan of the Dairy Cow}

In this study, the average number of calvings of a dairy cow was 3.6 and the average number of years of 
production (from first calving till death) was $4.3 \mathrm{yr}$ in 2009. This suggests a slightly longer lifespan than estimated in 1997 from milk recorded cows, with an average lactation number of 3.3 and a lifespan of around $5.5 \mathrm{yr}$ (FAWC, 2009). However, it should be noted that edits were made requiring cows to have milk records before functional longevity was estimated, which may lead results to be biased upwards by excluding animals that die close to calving. It is difficult to conclude whether dairy cows are living longer now compared with the early years of BCMS because average days of life is likely to be biased downwards in earlier years, due to a high proportion of young animals in the database. However, for recent years, enough opportunity time should have elapsed so that the majority of cow deaths are from animals that have been born since the start of BCMS recordings, thus, more reasonable estimates on average lifespan can be obtained.

We found that the majority of cow deaths were cull cows taken to the slaughterhouse (70\% of records), generally at the end of lactation; this percentage is likely comprised of both voluntary and involuntary culls, which may provide some financial return. Culling is generally greater in later stages of lactation when production is lower and declining, and pregnancy status of the cow is known. The remaining $30 \%$ were recorded as dead on an agricultural holding; these were termed involuntary culls and were the most devastating financial loss, offering no likelihood of revenue.

\section{Genetics of Survival - Heritability}

Replacement Heifers. Heifer survival is influenced by many different environmental factors, but it appears from this study that a genetic component contributes to survival, albeit small. The low heritability of heifer survival in this study $(\sim 0.01)$ was within the range of those studies from other countries (Hansen et al., 2003; Fuerst-Waltl and Sørensen, 2010; Henderson et al., 2011). Using linear models, Henderson et al. (2011) found a much lower heritability estimate for survival up until weaning (0.001) but a higher estimate from weaning until about 1 mo before calving (0.036) compared with the present study. The lower heritability of survival up to weaning was explained by the low frequency of deaths in that period $(2.7 \%)$. Lower heritability estimates, ranging from 0.001 to 0.008 , were obtained by Hansen et al. (2003) in Danish Holstein calves for different time periods up to 6 mo of age using a linear sire model. Also in Danish Holsteins, Fuerst-Waltl and Sørensen (2010) reported heritability estimates from a linear model ranging from 0.006 to 0.042 . Higher heritability estimates were obtained from the earliest time periods, 0 to $30 \mathrm{~d}$ and 31 to $180 \mathrm{~d}$, when the majority of losses occurred, and the highest heritability estimate (0.042) was obtained from the longest time period that spanned all time periods during rearing ( 1 to $1,200 \mathrm{~d}$ or until day before first calving). Heritability estimates of specific health problems during the rearing period are few, but heritability of respiratory disease in Norwegian Red calves up until $180 \mathrm{~d}$ of age was estimated by Heringstad et al. (2008) to be 0.05 on the underlying scale, and thus concluded that genetic evaluation of sires was feasible.

Heritability estimates on survival of calves are also few in beef cattle (Goyache et al., 2003; Guerra et al., 2006; Cervantes et al., 2010). The difference between dairy and beef analyses is that maternal effects (genetic or environmental) are likely to play a greater part in beef animals. Heritability estimates of calf survival at weaning were 0.05 in multibreed (Guerra et al., 2006) and 0.03 in Austuriana de los Valles (Cervantes et al., 2010) beef cattle, which were higher than the present study.

The low heritability of heifer survival can be explained by large environmental influences, as well as its classification as a binary trait. However, a variation was noted between sires in their breeding value for early survival, with $\sim 4 \%$ difference (proportion of daughter survival to d 750) between the top and bottom quartiles. Survival and fitness traits can be successfully selected for in practice and benefit from breeding program attributes, such as progeny testing and, potentially, genomic selection. Standardizing the environmental conditions and accuracy of recording could also increase heritability by reducing the nongenetic differences between animals. Overall, heifer losses could be combated quickly by improving the calf environment through better management. Genetic selection measures would have a slower effect but the small gains that accumulate over generations would be permanent.

Milking Cows. The heritability estimates for DPL and LS in this study were low (0.05 to 0.06 ), but were in the range of other longevity traits of other countries using linear models (0.02 to 0.11; Forabosco et al., 2009) and were consistent with studies from which LS was derived (Brotherstone et al., 1998). The heritability of DPL was slightly higher than LS, indicating that DPL captures slightly more of the genetic variation.

\section{Genetics of Survival - Genetic Correlations}

Replacement Heifers. Genetic correlations of heifer survival between time periods during the rearing period were positive and implied that traits were very similar. These results indicate that bulls with a low genetic merit for heifer survival (higher mortality) during the first period of rearing $(<6 \mathrm{mo})$ also have a 
tendency to have low genetic merit for heifer survival in a later period of rearing (e.g., 6 to $25 \mathrm{mo}$ ). Therefore, the observation period 2 to $180 \mathrm{~d}$ should be sufficient for sire selection, as a trait is most valuable when it is taken earlier in life. Hansen et al. (2003) found that adjacent time periods were more highly correlated. In US Holsteins, Henderson et al. (2011) considered 2 time periods, preweaning and postweaning (weaning $\sim 7 \mathrm{wk}$ ), and obtained a genetic correlation of 0.58 . Fuerst-Waltl and Sørensen (2010) studied Danish Holstein calves with 5 time periods defined from $2 \mathrm{~d}$ of age until calving (or up to $1200 \mathrm{~d}$ ) and obtained genetic correlations ranging from 0.49 to 0.92 . Results from these previous studies indicated that different genes were responsible for early and late postnatal mortality.

\section{Genetic Correlations Between Longevity} Traits. The genetic correlation between heifer survival ( 2 to $750 \mathrm{~d}$ ) with LS was favorable, indicating that bulls that sire daughters with longer productive lives also are likely to have calves that survive and become replacement heifers. This was likewise found by Henderson et al. (2011), with a lower correlation of 0.13 compared with 0.31 in this study. However, the moderate genetic correlation suggests that survival in the rearing period and survival in the milking herd are 2 different traits, likely to be affected by different sets of genes. Whereas, the genetic correlation between DPL and LS was high (0.97), indicating they are virtually the same trait. The favorable correlation between survival of the heifer calf and the milking cow might indicate a general disease resistance factor with a genetic component (Heringstad et al., 2005). Several nongenetic studies have associated calf illness with subsequent consequences in later life as a dairy cow (Correa et al., 1988; Hultgren and Svensson, 2009; Heinrichs and Heinrichs, 2011). Warnick et al. (1995) found calf diseases had no effect on subsequent first lactation milk yield, but disease-affected heifers had higher mortality during rearing and thus were less likely to enter the milking herd.

Using selection index theory (Hazel, 1943), the effect on early survival of selection on the national breeding goal (Wall et al., 2006) was estimated. Under the current breeding goal, lifespan is predicted to improve by 0.06 lactations per cow per annum. The estimated correlated response in early survival would be a $0.15 \%$ per annum improvement in the early life survival, even without a direct weighting on the trait in the index.

Longevity and Other Traits. Few studies have reported genetic associations between calf survival and dairy cow traits. In this study, genetic correlations were only significant between calf survival with milk production traits in addition to LS. Henderson et al. (2011) correlated heifer survival with predicted transmitting abilities of conformation and routinely evaluated traits.
Henderson et al. (2011) suggested that bulls with high genetic merit for feet and legs, a predictor of longevity in milking cows, were more likely to have calves that survive to maturity. Whereas, calves born from bulls with high genetic merit for linear body size conformation traits were less likely to survive than lower genetic merit bulls, expected to be associated with dystocia. Calves with higher growth rates and weights at weaning would be expected to be in better health than their herdmates, and this would be expected to continue as a dairy cow. However, Brotherstone et al. (2007) found a positive genetic association between growth rates at weaning with health disorders as a milking cow. The explanation given for this was that high production levels led to negative immune response. Studies have reported associations between polymorphisms located within the leptin gene with functional longevity (Szyda et al., 2011) and with still birth (Brickell et al., 2010). Increased prevalence of perinatal mortality could be due to selection on higher milk yield that is associated with a polymorphism within the leptin gene, but also conveys higher calf perinatal mortality (Buchanan et al., 2003; Brickell et al., 2010).

Correlations with DPL indicated that animals with a longer productive life tend to have lower SCC, a shorter calving interval, a fewer number of days to first service, require fewer inseminations, and have higher nonreturn rate. However, an antagonistic relationship existed between functional longevity of milk and fat yields. This could be due to higher yielding cows requiring better nutrition, which, when not met, leads to negative energy balance. This is associated with reduced immune response, making the cow more prone to disease (e.g., mastitis, lameness) or reduced fertility, and, for these reasons, cows might be culled prematurely.

\section{Trait Definition}

The appropriate definition of heifer survival would depend on the selection goal. Heifers recorded as dead on the agricultural holding could be assumed to have died from illness, thus a disease resistance component might be expected to be selected. However, given that the reason of death is unknown, this assumption should be treated with caution. Survival traits defined at different stages during heifer development may allow selection against certain diseases commonly prevalent during those times. Survival traits at younger ages may simultaneously select against gastro-intestinal and respiratory diseases. This study included some data sets with animals recorded dead on the agricultural holding and their contemporaries. However, it could be argued that all heifers that die or are culled that do not make it to the milking herd 
are wastage to the dairy industry. The farmer may obtain some salvage value for culling an animal but this would be far less than the opportunity cost associated, such as a heifer moving to the milking herd, selling surplus heifers as replacements to other herds, or rearing a cross-bred dairy-beef heifer. If sufficient data was available, maiden heifer fertility would be a suitable trait to include in future genetic evaluations for the later stages of heifer rearing.

Trait definitions and models of analysis for longevity of the dairy cow vary between countries. Most countries define longevity as productive life and analyze whether a cow is present or absent in the milk recording system with use of either a linear or a survival model (Forabosco et al., 2009). Both definitions of cow longevity, DL and DPL, are virtually the same trait, so it would make little difference which was used; although it might be more appropriate to use DPL as its definition is closest to LS and that used in other countries (Forabasco et al., 2009).

\section{Cattle Registration and Movement Data}

Before implementing new traits for genetic evaluation purposes arising from the information provided by BCMS data, it would be necessary to obtain permission for such uses, as well as being certain that such recording would continue far into the future. At present it is necessary to use milk-recorded data, and, in this study, only animals present in milk-recorded databases were used to obtain dam information; although progeny not present in milk-recorded herds may also provide useful information to genetic evaluations. However, in time, the BCMS database will have been established long enough to contain information on dams, such as age at calving, as they themselves would be recorded in the database as an animal. At present, it is not necessary for sire to be recorded in the database, although it is recorded by some farmers, and this could be a limitation of solely using BCMS data, thus simultaneous use of milk-recorded data would be essential.

\section{Benefits of Improving Longevity}

Increasing survival of both heifers during the rearing period and of milking cows is expected not only to have economic benefits but also to have social and environmental advantages. Rearing of replacement dairy heifers is a major variable cost, being the second highest variable cost of milk production after feed and forage (Chamberlain, 2012). Therefore, it is important to reduce mortalities of both heifers reared as replacements and cows in the milking herd to prevent such wastage.
The ability to predict future survival of a heifer early in life could prevent unnecessary investment in an animal and recover some expenses by meat rather than milk (Bach, 2011). Tozer and Heinrichs (2001) found that a reduction of the culling rate of milking cows from 25 to $20 \%$ reduced the net costs of raising replacement heifers by $25 \%$. Mortality not only has direct economic implications but affects the intensity of selection which can be applied to the milking herd. Improving the productive life of dairy cows improves the efficiency of dairy production by lowering replacement costs, capturing greater potential milk yields from mature cows, and allowing farmers more choice on which animals to retain and to breed replacements from. Animal health and welfare has an important role in future breeding goals and longevity is intrinsically related to welfare in some instances. Improving longevity would be expected to simultaneously reduce health and fertility problems. Improving efficiency by improving calf and cow longevity would also have environmental benefits (Garnsworthy, 2004).

\section{CONCLUSIONS}

In conclusion, the heritability estimates of all longevity traits analyzed in this study were low, yet improvement of the traits would be permanent and cumulative. Early survival was shown to be favorably correlated with productive life survival and milk yield traits and estimated correlated response of early survival of the current UK breeding goal was also favorable. This paper presents the first complete genetic analysis, including correlations with other traits in the breeding goal, of heifer survival in dairy cows. Further, genetic correlations with other production and fitness traits in the breeding goal were estimated. The study has found that BCMS data are a valuable resource that could have other potential uses in addition to the purpose for which it was established.

\section{ACKNOWLEDGMENTS}

The authors gratefully acknowledge the Rural Payments Agency's British Cattle Movement Service (Workington, UK) and the milk recording organizations in the United Kingdom that gave permission to use their data and also funding by Defra (London, UK) under the Sustainable Livestock Production LINK Programme, the Scottish Government (Edinburgh, UK), Cattle Information Service (CIS, Watford, UK) Cogent (Chester, UK), DairyCo (Warwickshire, UK), Genus (Cheshire, UK), Holstein UK (Rickmansworth, UK), and NMR (Chippenham, UK). 


\section{REFERENCES}

Bach, A. 2011. Associations between several aspects of heifer development and dairy cow survivability to second lactation. J. Dairy Sci. 94:1052-1057.

BCMS. 2012. Cattle Keeper's Handbook. Accessed Sep. 12, 2012. http://rpa.defra.gov.uk/rpa/index.nsf/vContentBy Taxonomy/BCMS**Publications\%20and\%20Guidance**Cattle\% 20Keeper's\%20Handbook**?OpenDocument.

Berglund, B., L. Steinbock, and M. Elvander. 2003. Causes of stillbirth and time of death in Swedish Holstein calves examined post mortem. Acta Vet. Scand. 44:111-120.

Brickell, J. S., N. Bourne, and N. D. C. Wathes. 2007. The incidence of calf mortality on dairy farms in southern England. Page 107 in Proc. British Society of Animal Science, Southport, UK. Cambridge University Press, Cambridge, UK.

Brickell, J. S., M. M. McGowan, D. U. Pfeiffer, and D. C. Wathes, 2009. Mortality in Holstein-Friesian calves and replacement heifers, in relation to body weight and IGF-I concentration, on 19 farms in England. Animal 3:1175-1182.

Brickell, J. S., G. E. Pollott, A. M. Clempson, N. Otter, and D. C. Wathes. 2010. Polymorphisms in the bovine leptin gene associated with perinatal mortality in Holstein-Friesian heifers. J. Dairy Sci. 93:340-347.

Brotherstone, S., M. P. Coffey, and G. Banos. 2007. Genetic parameters of growth in dairy cattle and associations between growth and health traits. J. Dairy Sci. 90:444-450.

Brotherstone, S., R. F. Veerkamp, and W. G. Hill. 1998. Predicting breeding values for herd life of Holstein-Friesian dairy cattle from lifespan and type. Anim. Sci. 67:405-411.

Buchanan, F. C., A. G. Van Kessel, C. Waldner, D. A. Christensen, B. Laarveld, and S. M. Schmutz. 2003. Hot topic: An association between a leptin single nucleotide polymorphism and milk and protein yield. J. Dairy Sci. 86:3164-3166.

Cervantes, I., J. P. Gutierrez, I. Fernandez, and F. Goyache. 2010 Genetic relationships among calving ease, gestation length, and calf survival to weaning in the Asturiana de los Valles beef cattle breed. J. Anim. Sci. 88:96-101.

Chamberlain, T. 2012. Understanding the economics of dairy farming Part 1: Income, costs and profit. Livestock 17:30-33. http:// dx.doi.org/10.1111/j.2044-3870.2012.00137.x.

Correa, M. T., C. R. Curtis, H. N. Erb, and M. E. White. 1988. Effect of calfhood morbidity on age at first calving in New York Holstein herds. Prev. Vet. Med. 6:253-262.

Eaglen, S. A. E., M. P. Coffey, J. A. Woolliams, and E. Wall. 2012. Evaluating alternative models to estimate genetic parameters of calving traits in United Kingdom Holstein-Friesian dairy cattle. Genet. Sel. Evol. 44:23. http://dx.doi.org/10.1186/1297-9686$44-23$.

Esslemont, R. J., and M. A. Kossaibati. 1996. Incidence of production diseases and other health problems in a group of dairy herds in England. Vet. Rec. 139:486-490.

FAWC (Farm Animal Welfare Council). 2009. Opinion on the welfare of the dairy cow. Accessed July 29, 2011. http://www.fawc.org.uk/ pdf/dcwelfar-091022.pdf.

Forabosco, F., J. H. Jakobsen, and W. F. Fikse. 2009. International genetic evaluation for direct longevity in dairy bulls. J. Dairy Sci. 92:2338-2347.

Fuerst-Waltl, B., and C. Fuerst. 2010. Mortality in Austrian dual purpose Fleckvieh calves and heifers. Livest. Sci. 132:80-86.

Fuerst-Waltl, B., and M. K. Sørensen. 2010. Genetic analysis of calf and heifer losses in Danish Holstein. J. Dairy Sci. 93:5436-5442.

Garnsworthy, P. 2004. The environmental impact of fertility in dairy cows: A modelling approach to predict methane and ammonia emissions. Anim. Feed Sci. Technol. 112:211-223.

Gilmour, A. R., B. J. Gogel, B. R. Cullis, and R. Thompson. 2006. ASReml User Guide Release 2.0. VSN International Ltd., Hemel Hempstead, UK.

Goyache, F., J. P. Gutiérrez, I. Alvarez, I. Fernández, L. J. Royo, and E. Gómez. 2003. Genetic analysis of calf survival at different preweaning ages in beef cattle. Livest. Prod. Sci. 83:13-20.
Guerra, J. L. L., D. E. Franke, and D. C. Blouin. 2006. Genetic parameters for calving rate and calf survival from linear, threshold, and logistic models in a multibreed beef cattle population. J. Anim. Sci. 84:3197-3203.

Gulliksen, S. M., K. I. Lie, L. Sølverød, and O. Østerås. 2008. Risk factors associated with colostrum quality in Norwegian dairy cows. J. Dairy Sci. 91:704-712.

Hansen, M., P. Madsen, J. Jensen, J. Pedersen, and L. G. Christensen. 2003. Genetic parameters of postnatal mortality in Danish Holstein calves. J. Dairy Sci. 86:1807-1817.

Hazel, L. N. 1943. The genetic basis for constructing selection indexes. Genetics 28:476-490.

Heinrichs, A. J., and B. S. Heinrichs. 2011. A prospective study of calf factors affecting first-lactation and lifetime milk production and age of cows when removed from the herd. J. Dairy Sci. 94:336341.

Henderson, L., F. Miglior, A. Sewalem, D. Kelton, A. Robinson, and K. E. Leslie. 2011. Estimation of genetic parameters for measures of calf survival in a population of Holstein heifer calves from a heifer-raising facility in New York State. J. Dairy Sci. 94:461-470.

Heringstad, B., Y. M. Chang, D. Gianola, and G. Klemetsdal. 2005. Genetic analysis of clinical mastitis, milk fever, ketosis, and retained placenta in three lactations of Norwegian Red cows. J. Dairy Sci. 88:3273-3281.

Heringstad, B., Y. M. Chang, D. Gianola, and O. Østerås. 2008. Short communication: Genetic analysis of respiratory disease in Norwegian Red calves. J. Dairy Sci. 91:367-370.

Hultgren, J., and C. Svensson. 2009. Lifetime risk and cost of clinical mastitis in dairy cows in relation to heifer rearing conditions in southwest Sweden. J. Dairy Sci. 92:3274-3280.

Lombard, J. E., F. B. Garry, S. M. Tomlinson, and L. P. Garber. 2007. Impacts of dystocia on health and survival of dairy calves. J. Dairy Sci. 90:1751-1760.

Menzies, F. D., D. G. Bryson, T. McCallion, and D. I. Matthews 1996. Mortality in cattle up to two years old in Northern Ireland during 1992. Vet. Rec. 138:618-622.

Ortiz-Pelaez, A., D. G. Pritchard, D. U. Pfeiffer, E. Jones, P. Honeyman, and J. J. Mawdsley. 2008. Calf mortality as a welfare indicator on British cattle farms. Vet. J. 176:177-181.

Philipsson, J., J. L. Foulley, J. Lederer, T. Liboriussen, and A. Osinga. 1979. Sire evaluation standards and breeding strategies for limiting dystocia and stillbirth. Report of an E.E.C./E.A.A.P. working group. Livest. Prod. Sci. 6:111-127.

Pollott, G. E. 2011. Short Communication: Do Holstein lactations of varied lengths have different characteristics? J. Dairy Sci. 94:6173-6180

Sivula, N. J., T. R. Ames, W. E. Marsh, and R. E. Werdin. 1996. Descriptive epidemiology of morbidity and mortality in Minnesota dairy heifer calves. Prev. Vet. Med. 27:155-171.

Svensson, C., A. Linder, and S. O. Olsson. 2006. Mortality in Swedish dairy calves and replacement heifers. J. Dairy Sci. 89:4769-4777.

Szyda, J., M. Morek-Kopec, J. Komisarek, and A. Zarnecki. 2011 Evaluating markers in selected genes for association with functional longevity of dairy cattle. BMC Genet. http://dx.doi. org/10.1186/1471-2156-12-30.

Tozer, P. R., and A. J. Heinrichs. 2001. What affects the cost of raising replacement dairy heifers: A multiple-component analysis. J. Dairy Sci. 84:1835-1844.

Van der Fels-Klerx, H. J., S. W. Martin, M. Nielen, and R. B. M. Huirne. 2002. Effects on productivity and risk factors of bovine respiratory disease in dairy heifers; a review for the Netherlands. Neth. J. Agric. Sci. 50:27-45.

van der Poel, W. H., W. G. Middel, and Y. H. Schukken. 1999. Antibody titer against bovine respiratory syncytial virusin colostrums-fed dairy calves born in various seasons. Am. J. Vet. Res. 60:1098-1101.

Visscher, P., R. Thompson, H. Yazdi, W. G. Hill, and S. Brotherstone. 1999. Genetic analysis of longevity data in the UK: Present practice and considerations for the future. Pages 16-22 in Interbull Bulletin 21. Interbull, Jouy-en-Josas, France. 
Wall, E., S. Brotherstone, and M. P. Coffey. 2006. Development of a robustness index for UK dairy cattle. In Proc. 8th World Congr. Genet. Appl. Livest. Prod., August 13-18, 2006, Belo Horizonte, Minas Gerais, Brazil, Communication 01-10. Federal University of Minas Gerais, Belo Horizonte, Brazil.

Wall, E., S. Brotherstone, J. F. Kearney, J. A. Woolliams, and M. P. Coffey. 2005. Impact of nonadditive genetic effects in the estimation of breeding values for fertility and correlated traits. J. Dairy Sci. 88:376-385.

Waltner-Toews, D., S. W. Martin, and A. H. Meek. 1986. Dairy calf management, morbidity and mortality in Ontario Holstein herds. II. Age and seasonal patterns. Prev. Vet. Med. 4:125-135.
Warnick, L. D., H. N. Erb, and M. E. White. 1995. Lack of association between calf morbidity and subsequent first lactation milk production in 25 New York Holstein herds. J. Dairy Sci. 78:2819-2830.

Wathes, D. C., J. S. Brickell, N. E. Bourne, A. Swali, and Z. Cheng. 2008. Factors influencing heifer survival and fertility on commercial dairy farms. Animal 2:1135-1143.

Wells, S. J., D. A. Dargatz, and S. L. Ott. 1996a. Factors associated with mortality to 21 days of life in dairy heifers in the United States. Prev. Vet. Med. 29:9-19.

Wells, S. J., L. P. Garber, and G. W. Hill. 1996b. Health status of preweaned dairy heifers in the United States. Prev. Vet. Med. $29: 185-199$. 